\title{
Scaffolding Student Writing
}

ELAINE A. PRICE

Chignecto Central Regional School Board

MARY JANE HARKINS

Mount Saint Vincent University

\begin{abstract}
Improvement of student writing continues to be a focus for teachers. An effective approach to scaffolding student writing is through the utilization of researched-based tools and strategies. This study examined the effectiveness of teacher-prepared criteria/information handouts to the use of a teacher-adapted graphic organizer for improvement of student book-response writing. Through a student-completed survey generalization, or environmental change, was also investigated. Evidence supports generalization, and findings indicate significant increases within student book-response writing for the number of areas included for analysis, number of points made, and number of supporting points. Implications for students, teachers, and future research are considered.
\end{abstract}

Writing is a powerful tool and an essential part of a balanced literacy program. As Graham and Harris (2005) stress, student writing is a complex process that includes "planning, monitoring, evaluating and revising text" (p. 1). Proficiency in writing is a key to school success; however, many students struggle with learning to write. Encouraging students to express themselves through writing helps them to connect writing to reading, speaking, and viewing print, as writing is a critical component of effective communication. One instructional approach to improve students' writing abilities is for teachers to utilize a range of strategies that scaffold, or provide a fundamental layer of support for students' writing. Scaffolding student writing allows the teacher to balance teacher direction and independence as s/he aligns instruction with the students' needs and abilities. Teacher-led instruction decreases as students acquire new skills. One such strategy is the use of a graphic organizer as a scaffold to provide support and guidance to enhance students' understanding of the function and conventions of writing.

The root of organizer use is credited to David P. Ausubel by several researchers (Dunston, 1992; Kim, Vaughn, Wanzek, \& Wei, 2004; Merkley \& Jefferies, 2000). He developed the use of a prose format organizer, presented as background information and written at a higher level of complexity - more abstract than the material/concept to be learned (Alvermann, 1981; Dunston, 1992). By the 1970's interest had increased so that researchers were studying a variety of different organizers, as a result of Ausubel's study with advance organizers.

In the 1980s, due to the progress of brain functioning research, the schema theory was used to explain how we learn, based on our previous experiences and background knowledge or schema (Harvey \& Goudvis, 2000). As brain functioning research continued, specifically targeting comprehension of text, suggestions for instructional strategies result, which not only support the use of organizers prior to reading (Alvermann \& Boothby, 1983; Simmons, Griffin \& 
Kameenui, 1988) to activate schema, but also after reading for the purpose of retrieval (Dunston, 1992; Moore \& Readence, 1984; Simmons et al., 1988). Teacher-prepared structured overviews or outlines emerged to stimulate schema (Simmons et al., 1988) and later developed into the graphic organizer (Dunston, 1992; Moore \& Readence, 1984).

Teacher-completed graphic organizers have been used for a variety of purposes: improvement in comprehension, retention of reading, deeper processing of information due to student engagement in generative cognitive processing (Mayer, 2005), and/or improvement in writing. Alvermann and Boothby (1986) found that graphic organizers, at least partly constructed by the student, given to students before and after the reading of material to be learned, increases comprehension. Both Bos and Vaughn (2006) indicated support of graphic organizer use before, during, and after reading, to increase the learning performance of students with learning and behavior problems. As a prewriting activity, Graves (1994) supported the use of webs for brainstorming about topics, while Adams, Power, Reed, Reiss, and Romaniak (1996) found the use of graphic organizers for writing helped students to develop a complete and organized story.

As organizer use continues to be studied by more and more researchers, the merit of organizers is questioned. Rice (1994), and Griffin and Tulbert (1995), after reviewing the results of several studies regarding graphic organizer use, reported the results as inconclusive due to variations in treatment designs and teaching/learning events. In addition, the results of a study by Simmons et al. (1988) on the effects of teacher-constructed pre and post-graphic organizers and teacher instruction on sixth-grade students' comprehension regarding recall of science content, indicate that teacher-constructed graphic organizers presented before or after the reading of the textual information are no more effective than teacher instruction. They further found that the amount of time necessary to teach graphic organizer use is problematic.

Anderson and Armbruster (1984) suggested that one should question how and why organizers work. This notion suggests that teachers examine the best style of graphic organizer to use based on purpose, then tailor that organizer to specifically address the intended outcomes. The research on the use of graphic organizers does tend to relate to reading, so we decided to focus on the use of a graphic organizer for scaffolding student writing. The purpose of the study was to examine two strategies for improving student writing: the use of a book response analysis information handout compared to the use of a two-page graphic organizer (Price, 2008) for improvement of student writing. These strategies were designed to be teacher-friendly, readily accessible, and easily adapted for all students including struggling writers.

This study provides a strategy to help teachers to identify and provide an intervention for specific difficulties students encounter when engaged in the writing process as well as a pedagogical approach that encourages teachers to engage in research. As teachers reflect and research their practice, they foster an evidence-based approach to teaching.

\section{Design of the Study}

A formative experimental model (Newman, 1990; Reinking \& Pickle, 1993; Reinking \& Watkins, 1996) was chosen over a conventional experimentation model due to the broad scope, which allowed for greater situational factors such as participants reading their novel at home. This model permitted participant input aiding any necessary reshaping of an implementation and/or structure of an intervention during the study. For this reason, use of a Researcher's Logbook was included in the study to note details and any observations of the experiment that involved reshaping strategies and/or instruments. 
In order to address areas of analysis, expanding ideas, and quotes/connecting experiences in the students' book-response writing, Price (2008) customized a herringbone-style graphic organizer to create the Herringbone Book Response Organizer (see Appendix A). To support student writing, eight areas of analysis were included on the lines extending from the backbone of the organizer, with an additional three lines projecting from each area of analysis for topic sentence key words, a supporting quote, and a personal connection. A second page, the Expanding Ideas Organizer (Price, 2008 see Appendix B), was created to assist participants with expanding their paragraphs to include additional detail about each of the eight areas of analysis.

Further intent of the design of this two-page Herringbone Book Response Organizer, hereinafter referred to as the two-page organizer, was to support paragraphing of ideas, the writing of topic sentences for paragraphs, and the organization of ideas within each paragraph. To facilitate novel analysis and essay writing, a teacher-created Book Response Analysis Information handout (Price, 2008 see Appendix C) and Book Response Essay Format handout (Price, 2008 see Appendix D) were created as participant references. In addition, explicit teaching of note-taking and graphic organizer use was included as these were areas noted as limitations in other studies (see e.g., Dunston, 1992). To investigate generalization/ environmental change(s), and/or continued use of the treatments used in this study (Newman, 1990; Reinking \& Watkins, 1996), a Student Questionnaire (Price, 2008 see Appendix E) was developed as the final component of the study.

\section{Instruments}

This study involved the following instruments:

a) The teacher-created Book Response Analysis Information handout and Book Response Essay Format handout were created because of the limited repetitions of information within mini-lessons, and due to the limitation of student recall (Berkowitz, 1986). The Book Response Analysis Information handout was also chosen as an instrument/intervention because of the research supporting its use (Alvermann \& Boothby, 1983; Merkley \& Jefferies, 2000; Simmons et al., 1988).

b) The herringbone style of organizer was selected due to its simplistic format enabling each category (eight areas of analysis) to be further divided into three parts: main point, supporting quote, and personal experiences/connections. The pre-printed categories and cuing for the three supporting parts were included on this organizer as a result of the research on cognitive load theory involving risk of extraneous processing (Stull \& Mayer, 2007). Furthermore, the two-page organizer was designed to be participant completed based on the activity theory, which suggests that students learn more deeply when fully engaged (Stull \& Mayer, 2007).

c) To facilitate replication of the study, the Researcher's Logbook was included to note each step of the study and to note any observations, including those that might suggest a need for reshaping the study's strategies and/or instruments.

d) The Student Questionnaire was developed to investigate factors regarding the writing of rough copies, redoing of final copies, having a mindset toward graphic organizers, and to investigate this study's instruments that participants preferred and/or intended to continue to use for book-response writing. 


\section{Participants}

Ninety-eight students within four, seventh-grade, English Language Arts classes completed the same activities as the selected participants. Twelve of these students ( 8 boys and 4 girls), 11-12 years of age, were chosen to be participants in this study; however, only ten of the twelve participated in the full study. These twelve students were identified as Struggling Writers based on an assessment from the local Department of Education. No control group was used due to this study being a preliminary investigation to determine the effectiveness of the interventions with struggling readers in an inclusive classroom environment.

\section{Procedure}

The procedure involved the following two stages:

Stage 1 - book response writing with use of Book Response Analysis Information handout

- During the months of May and June the ten participants participated in this study for one hour per day.

- Before reading the assigned novel, Hatchet, participants were given instruction on the criteria and format for book report analysis, quoting, and note taking. Instruction involved mini lessons, the use of color-coded adhesive notes, and the highlighting of key words of the Book Response Analysis Information handout.

- The participants made notes regarding the criteria for analysis while reading the novel both at home and in class, with the opportunity of using the handout.

- Upon completion of reading the novel, participants set up a loose-leaf page for each of the eight areas of analysis and transferred all their (adhesive) notes to the appropriate loose-leaf page. *

*Through this activity, several participants realized that they had not collected enough information for each area, but few chose to reread and re-gather for missing information before writing the rough copy of their book response.

- Based on the realization that participants were not knowledgeable about the format for essay/response writing, the Book Response Essay Format handout was created by the teacher and distributed to participants. During the time they were writing their first rough copy, this handout was reviewed and highlighted through mini lessons.

- Participants edited their rough copies, then wrote a final copy of their response and submitted both copies.

- Written work was completed during class time and collected at the end of each class to ensure that the work participants completed was done without assistance. For an example of participant writing, with only the use of the Book Response Analysis Information handout as a reference, see Appendix F.

Stage 2 - book response writing with use of the two-page organizer

- Format for response writing, areas of analysis, quoting, use of best connections/experiences, and completion of the two-page organizer were reviewed through mini lessons.

- Participants were asked to complete the two-page organizer. Their information handouts, Book Response Essay Format, and Book Response Analysis Information were available to them. The final copy of their first book response (without the use of the two-page 
organizer) was returned to each participant, unmarked by the teacher, so they could use the information to complete their two-page organizer; however, the response was collected before any rough-copy writing was started.

- Mini lessons were given on the format for response writing and how to write directly from the two-page organizer. Participants wrote a rough copy of their book response, edited their work, and wrote a final copy. Then, each participant passed in their two-page organizer, a rough copy, and final copy of their book response for assessment. For an example of a participant's completed two-page organizer and final copy of his/her book responses see Appendices $\mathrm{G}$ and $\mathrm{H}$.

\section{Data Collection/Analysis}

Each participant's final copy of his/her first book response, written with the use of the Book Response Analysis Information handout only, and each final copy written with the twopage organizer and the Book Response Analysis Information handout was assessed to determine: 1. the number of areas for analysis; 2 . the number of expanding points/ideas included under each area of analysis; and 3. the number of supporting quotes and experiences/connections. Using a tally sheet, each item was scored as one point.

The Minitab program and its worksheets were used to process and analyze the statistical data. One-sample $t$ tests were performed to determine the mean of entries for areas of analysis stated, number of expanding ideas, and number of quotes and/or personal experiences/connections with the use of the two-page organizer, then without its use, and deviation scores determined for each. These scores were used in an effect size-formula to determine the effect of use of the two-page organizer on book-response writing compared to not using this organizer. Results were then compared to an effect scale $(0.20=$ small change/effect; $0.50=$ medium change/effect; and $0.80=$ large change/effect) to determine the level of effect of use of the two-page organizer regarding areas of analysis, expanding ideas, and support of points on book-response writing. Through a t test of matched pairs (number of entries for analysis, expanding ideas, and support of points) the standard error, standard deviation, and $\mathrm{p}$ value scores were calculated for book response writing, followed by a determination of significance. The level of significance, for these t tests, was set at 0.05 .

The Student Questionnaire was designed so yes/no answers would/would not indicate an inhibitor factor showing impact of use of this study's instruments. The results from these questionnaires were used to indicate possible impact of effectiveness of use of the interventions/instruments for improvement of participant book-response writing. Evidence to verify possible environmental change was also investigated through an analysis of the tally sheets regarding the questions on the Student Questionnaire dealing with instruments/interventions participants preferred, or chose related to achievement, for future response writing.

\section{Findings and Discussion}

The impact of the interventions used in this study for student writing will be discussed through the following items: areas of analysis, expanding points/ideas under each area of analysis, and supporting points using quotes and experiences/connections. Findings, from the Student Questionnaire, will also be discussed regarding effectiveness of use of the interventions, environmental change, and possible restructuring of interventions. 


\section{Areas of Analysis}

From the participants' tally sheets, individual scores for areas of analysis range from 2 to 8 entries without use of the two-page organizer, with total number of entries for participants at 48. These scores were compared to the range of 3 to 12 entries with the use of the organizer, and a total number of entries at 88, indicating a total increase of 40 entries when using the two-page organizer. The mean number of entries at 8.8 (Table 1) and standard deviation of 3.12 (Table 2), with the use of the organizer, were compared to the mean number of entries at 4.8 (Table 1) and standard deviation of 1.619 (Table 2), without the use of the two-page organizer, through effect size. Results indicate that the level of effect with use of the two-page organizer regarding areas of analysis for book-response writing is large at 1.688 (Table 1).

\section{Expanding Ideas}

According to the tally sheets for expanding ideas, individual participant scores range from 6 to 21 entries with a total of 127 entries/ideas, without use of the two-page organizer. These scores were compared to the range of 3 to 17 individual entries and a total of 207 entries/ideas showing a total increase of 80 entries/ideas made by participants about the areas of analysis with the use of the two-page organizer. The mean number of entries of 20.70 (Table 1) and standard deviation of 6.63 (Table 2), with the use of the organizer, were compared to the mean number of entries at 12.7 (Table 1) and standard deviation of 4.55 (Table 2), without the use of the organizer, through effect size. Results indicate that the level of effect with use of the two-page organizer regarding expanding ideas for book-response writing is also large at 1.43 (Table 1).

\section{Support of Points}

The tally sheets for support of points indicate individual scores range from 0 to 12 entries with a total number of entries at 52, without the use of the two-page organizer. These scores were compared to the range of 3 to 30 entries for individuals and a total of 100 entries showing a total increase of 48 quotes/connections, with the use of the two-page organizer. Results indicate that the level of effect with the use of the two-page organizer regarding support of points for book-response writing is large, as well, at 0.862 (Table 1). 
Table 1

Book Response - Number of Entries Between no use and use of the Herringbone Book Response Organizer (two-page organizer)

\begin{tabular}{|l|l|l|l|l|}
\hline & $\begin{array}{l}\text { Mean } \\
\text { Number } \\
\text { Entries no } \\
\text { Organizer }\end{array}$ & $\begin{array}{l}\text { Mean } \\
\text { Number } \\
\text { with Gr. } \\
\text { Organizer }\end{array}$ & $\begin{array}{l}\text { Average } \\
\text { Diff. with } \\
\text { use of Gr. } \\
\text { Organizer }\end{array}$ & $\begin{array}{l}\text { Level of Effect with } \\
\text { Graphic Organizer }\end{array}$ \\
\hline $\begin{array}{l}\text { Areas of Analysis } \\
(8)\end{array}$ & 4.8 & 8.8 & 4 & 1.68 \\
\hline $\begin{array}{l}\text { Expanding Ideas } \\
(24)\end{array}$ & 12.7 & 20.7 & 8 & 1.43 \\
\hline $\begin{array}{l}\text { Support of Points } \\
(8-16)\end{array}$ & 5.2 & 10 & 4.8 & 0.86 \\
\hline Totals & 22.7 & 39.5 & 16.8 & 2.39 \\
\hline
\end{tabular}

Note. effect scale $0.20=$ small change/effect; $0.50=$ medium; and $0.80=$ large

Table 2

Book Response - increase of number of entries between no use and use of the Herringbone Book Response Organizer (two-page organizer)

\begin{tabular}{|l|l|l|l|l|}
\hline Criteria & $\begin{array}{l}\text { Mean (Diff. } \\
\text { with Gr.Org.) }\end{array}$ & SE & SD & p-Value \\
\hline Areas of Analysis & 4 & 1.11 & 3.5 & 0.003 \\
\hline Expanding Ideas & 8 & 1.33 & 4.22 & 0 \\
\hline Support of Points & 4.8 & 1.85 & 5.87 & 0.015 \\
\hline Totals & 16.8 & 2.74 & 8.68 & 0 \\
\hline
\end{tabular}

The increase of number of entries by each participant indicates improvement of each book response as a result of using the two-page organizer. From the mean increases previously mentioned, and from the results of the effect formula and effect scale indicating a large effect, evidence supports strong improvement when the participants in this study used the two-page organizer for book-response writing compared to when one was not used. Although not formally assessed as part of this study, it appears that the layout of the two-page organizer does support paragraphing of ideas, organization of ideas, and the writing of topic sentences for paragraphs, as can be seen in comparing excerpts from a participant's book-responses written with and without the two-page organizer (see Appendices F, G, H).

Using the Book Response Analysis Information handout but without the use of the twopage organizer, this participant includes his/her unsupported comments about plot/problems and questions/opinions in the introductory paragraph, rather than developing them within separate paragraphs. 


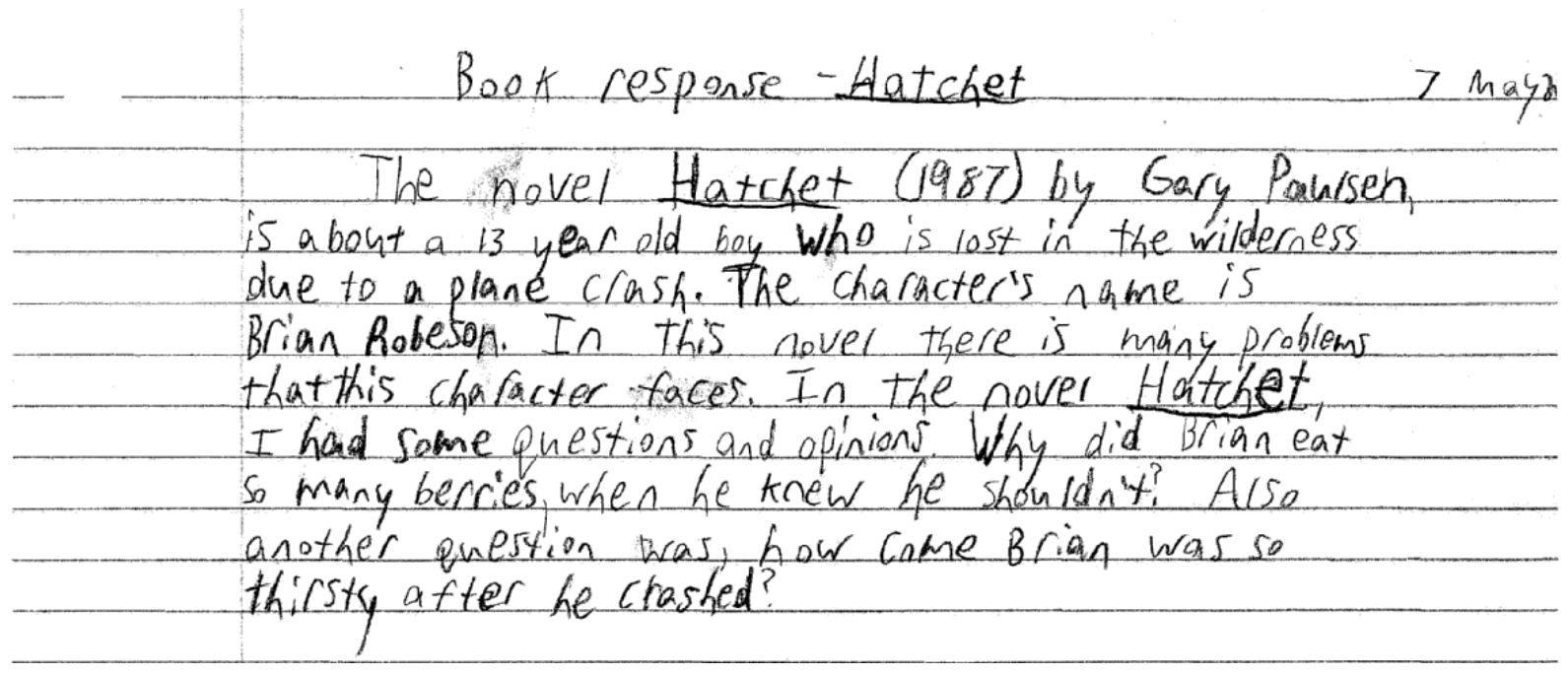

Using the two-page organizer, the same participant includes topic sentences, and develops and supports both areas of analysis (problems/plot and questions/opinions) in separate paragraphs in the following examples of his/her book response.

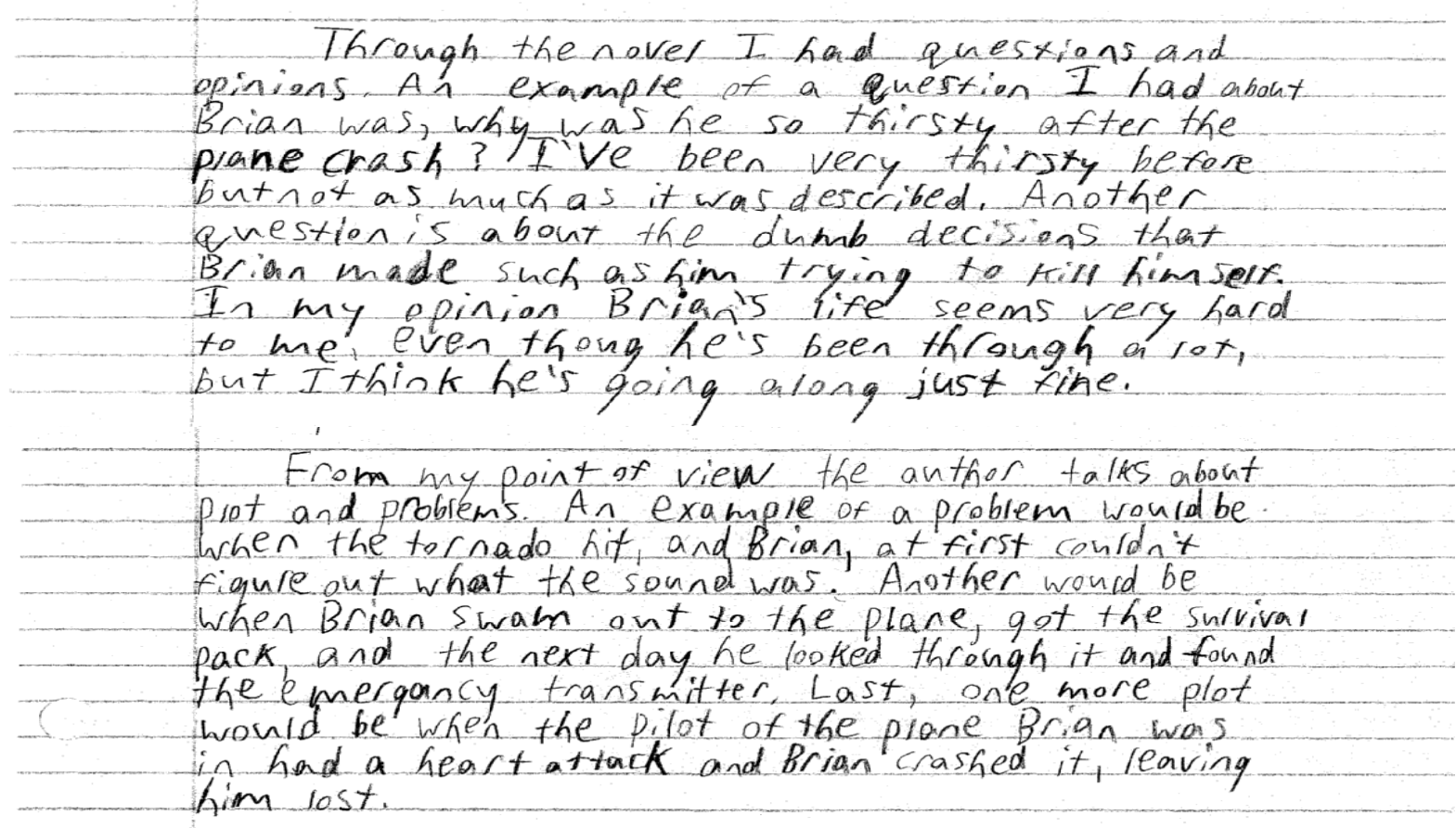


In a second example, while using the Book Response Analysis Information handout but without the use of the two-page organizer, a second participant includes unsupported, onesentence comments about flashbacks and about meaning as techniques used by the author.

(pg. 1)

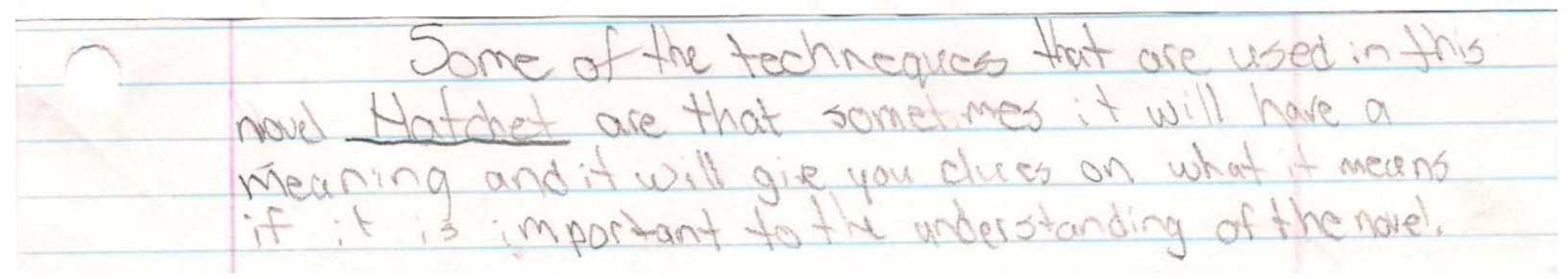

(cont. pg. 2)

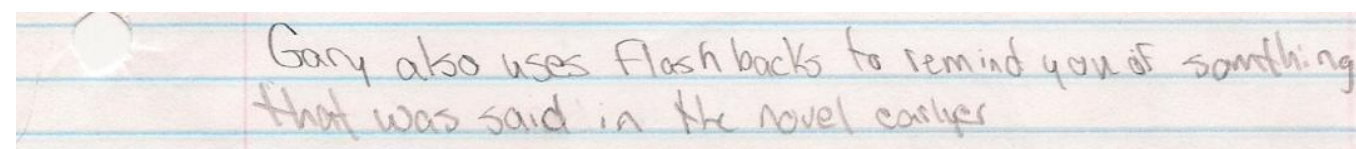

However, with use of the two-page organizer, this participant clearly develops his/her points, and adds support with a quote from the novel within his/her book response.

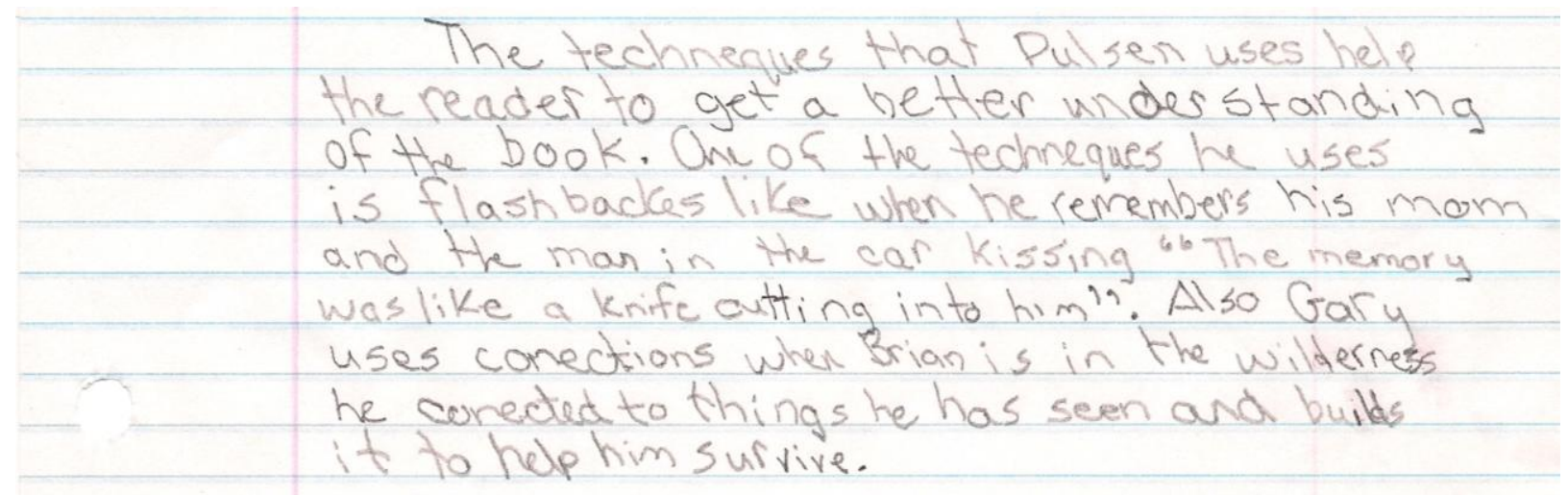

Finally, in a third example, with the use of the Book Response Analysis Information handout but without the use of the two-page organizer, the participant includes points about the main character getting into trouble, but omits a clear introductory sentence and development of ideas to support the author's use of description. 


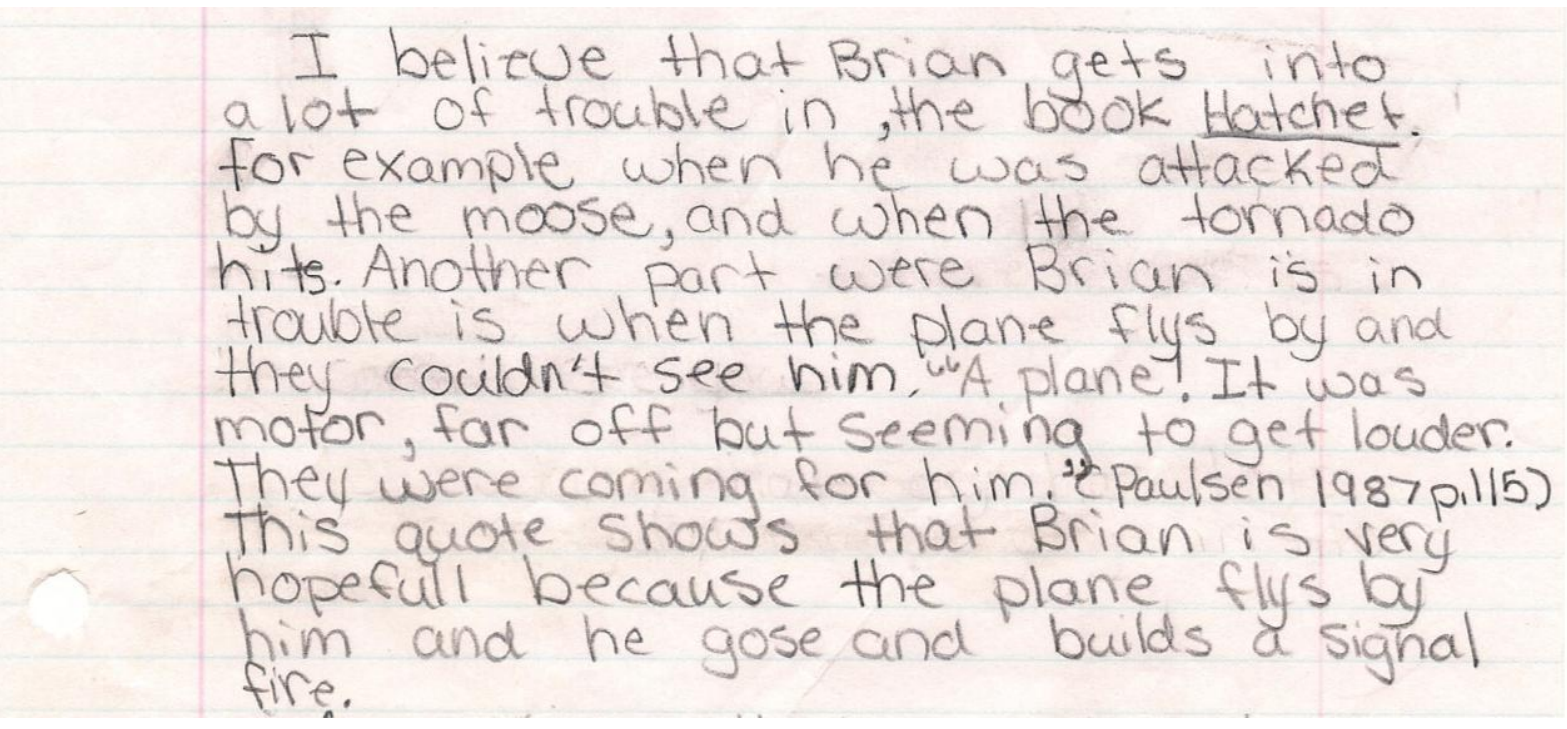

On the other hand, with use of the two-page organizer, this participant includes a topic sentence that clearly points out the main idea of the paragraph, develops his/her points with a supporting quote from the novel, and adds a personal connection within his/her book response.

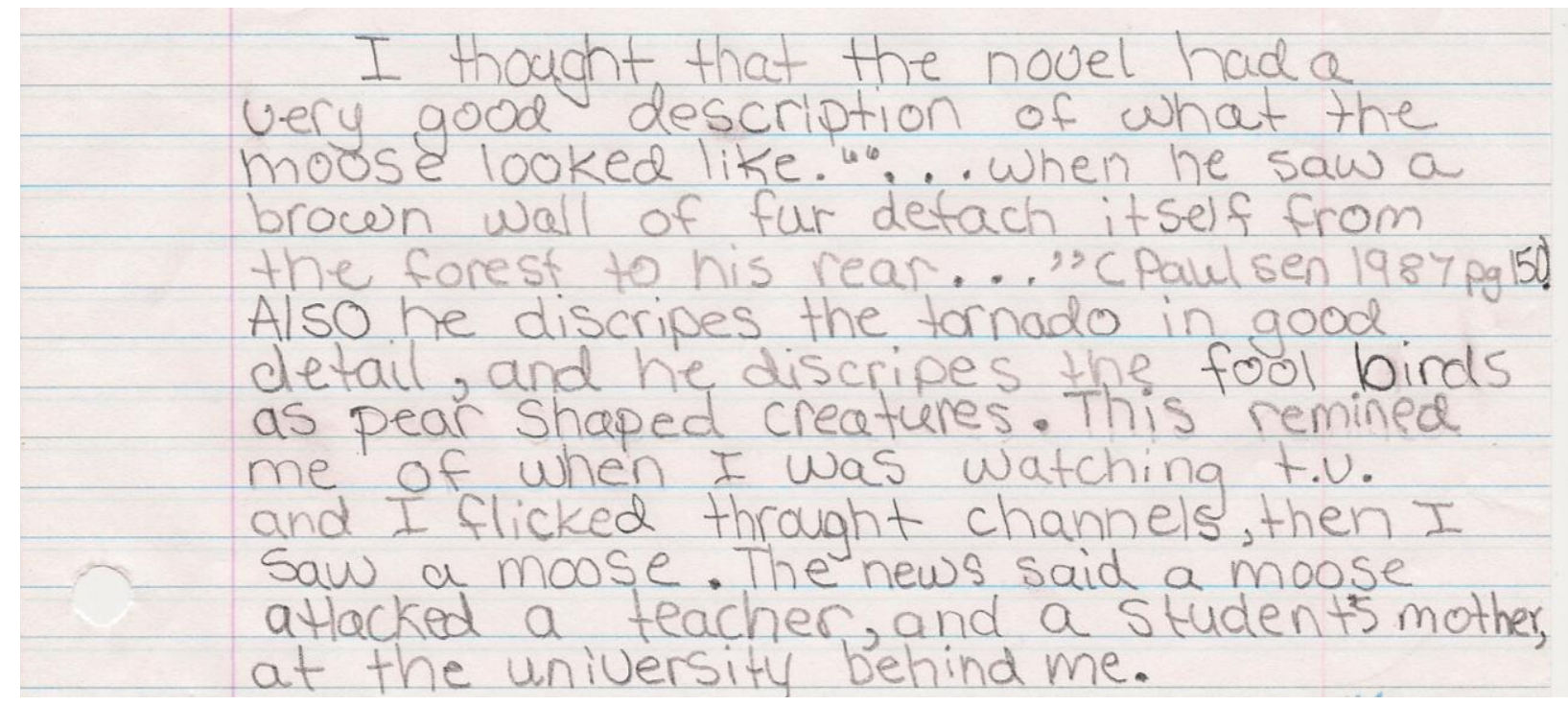

Although the structure of the two-page organizer is not learner generated, the benefits of its use continues, as generative (or germane) processing occurs with the completion of the organizer (Stull \& Mayer, 2007). Students are challenged cognitively through the development of paragraphs, the organizing of those paragraphs within their pieces, and the choosing of best connections to support points/ideas for their responses.

The positive effect of the two-page organizer compared to the use of the Book Response Analysis Information handout (containing the same criteria but in prose format) was further 
identified by the Researcher's Logbook where it was noted that participants tended to reread for missing information while filling in the two-page organizer. It was also observed that some participants appeared to be unaware they had not included all of the suggested criteria for a book response until they began their second book response using the two-page organizer.

\section{Student Questionnaire}

Factor impact on effectiveness of use of interventions.

From the questionnaires completed by each participant, their answers indicated a total of only 12 out of a possible 70 inhibitor factors; factors designed to indicate impact on effectiveness of use of an intervention. Questions regarding normally doing a rough copy, and normally editing a rough copy for a book response were the two questions participants chose the most, supporting inhibitor factors. Due to the low number of total inhibitor factors indicated by the Student Questionnaire results in the study, a clear correlation cannot be established to support an impact of participants normally writing a rough copy, having to redo a good (final) copy, or having a mindset toward graphic organizer use, on effectiveness of use of the interventions used for improvement of book-response writing in this study.

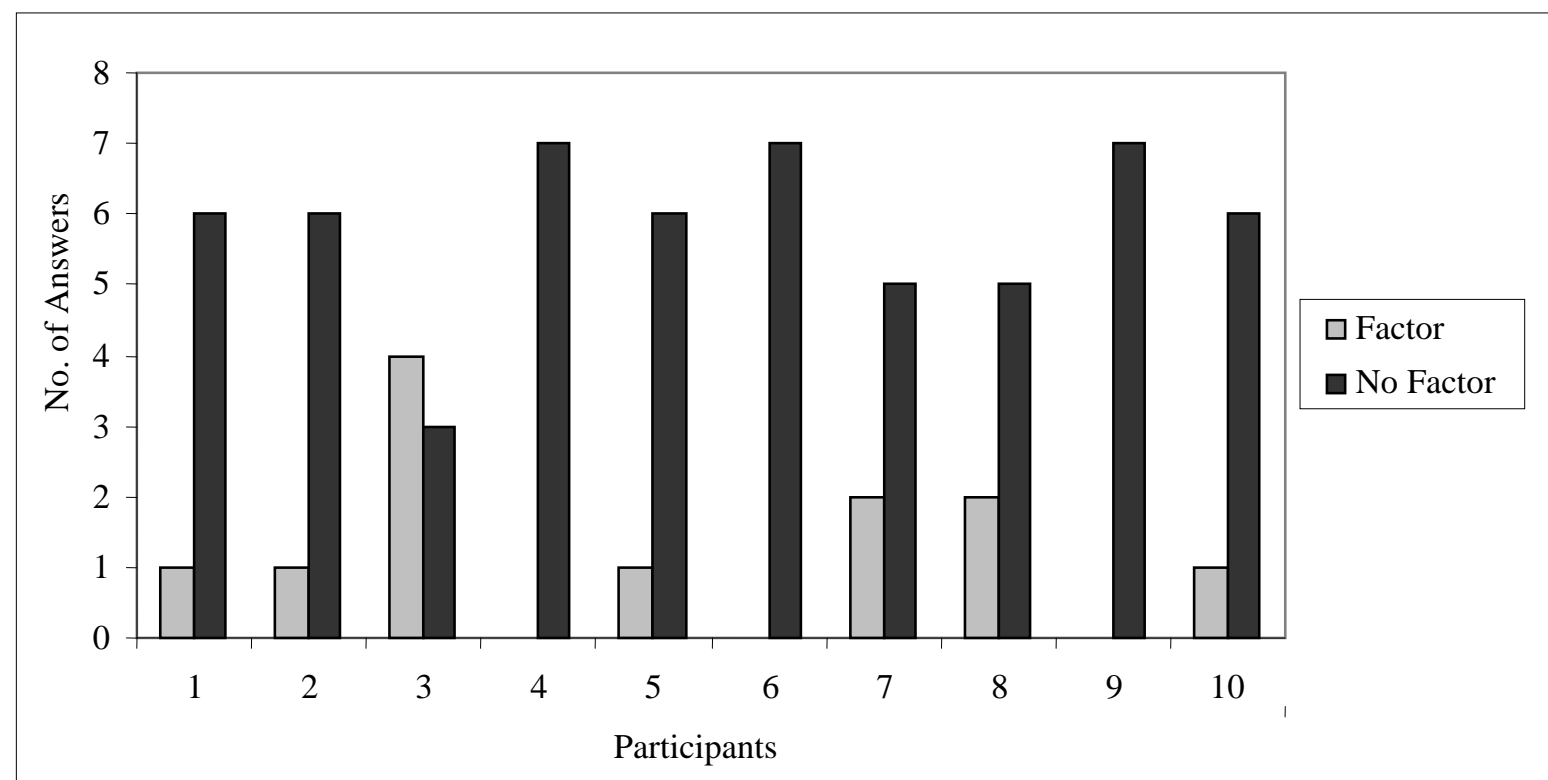

Figure 1. Inhibitor factor/no factor from answers to questions 1-7 on Student Questionnaire for each participant

Environmental change - preference and future use of interventions.

Through an analysis of the Student Questionnaire results, with use of Minitab worksheets and a tally sheet for those questions dealing with the interventions (two-page organizer and the Book Response Analysis Information handout), participants' preference or choice related to achievement was investigated as evidence to verify possible environmental change. 
According to the questionnaire results, 10 out of 10 participants felt that using the twopage organizer improved their book response writing, even though 9 out of 10 indicated that they had not used a graphic organizer for writing a book response before this study, and 6 out of the 10 participants indicated that they had not written a book response prior to this study. When participants were asked which intervention, the two-page organizer or the Response Analysis Information handout, they preferred to use for book-response writing, 10 out of 10 chose the use of the two-page organizer, and 10 out of 10 indicated that they will use a graphic organizer for book-response writing in the future. Therefore, from the results of the questionnaires, environmental change (future use of a graphic organizer for book-response writing) was evident in this formative experiment.

\section{Restructuring of interventions.}

This study determined that the participants, due to level of knowledge, required a format information handout for response writing, as well as a reference explaining criteria for bookresponse writing they could refer to after mini lessons. Based on the Researcher's Logbook and results of the questionnaires, in terms of structural reshaping of the interventions used in this study, no reshaping was indicated as being needed for the two-page organizer for response writing.

\section{Summary and Comments}

As this study followed a formative rather than scientific experimental model, when it was determined that the writing scaffolding, or layers of support for participants, needed to include instruction and an information handout to use as a reference regarding format of book-response writing, they were able to be included. The two-page organizer was found to cause the greatest improvement for book-response writing, with mean increases in number of entries for areas of analysis, expanding ideas, and support of points each being significant. In addition, participants tended to include more of the suggested criteria for the book response when the two-page organizer was used than when criteria were presented only in prose format. The preprinted, teacher-prepared categories on the two-page organizer appeared to be beneficial for participants in helping them to include all the suggested criteria. In spite of $90 \%$ of participants indicating that they had not used a graphic organizer for writing a book response before this study and only $60 \%$ indicating they had written a book response prior to this study, $100 \%$ of the participants felt that using the two-page organizer improved their book-response writing. As well, all participants indicated that they preferred using a graphic organizer compared to just having a teacher-prepared (prose-style) information handout regarding the criteria of analysis for bookresponse writing. Every participant also indicated that $s /$ he would use a graphic organizer in the future for book-response writing, supporting the occurrence of an environmental change - future use of an intervention for book-response writing, as a result of this study.

Some expected benefits of this easy-to-follow, criteria-specific two-page organizer could extend to parents, while supporting their children during homework; to students, during peer editing sessions or while helping students at other grade levels; and to Learning Center or Support Teachers, while assisting students in both classroom and pull-out situations. As well, the time educators need to spend assisting with organization of ideas within paragraphs, development of topic sentences for paragraphs, and expansion and support of ideas in student writing is decreased when students write directly from this two-page organizer, since each section forms a paragraph, and each main point on the herringbone becomes a topic sentence. 
Furthermore, due to the resulting organization of paragraphs the amount of editing and rewriting is reduced, often issues that cause reluctant writers to derail.

Since the completion of this study, the impact has been evidenced by requests for the two-page organizer from the participants, students from a variety of grade levels, and teachers (including support teachers and non-English Language Arts teachers). Due to the two-page organizer being so easy to tailor, future research could examine other types of responses using this organizer style (herringbone and expanding ideas). Cross-curricular examination of these styles of organizers might yield interesting results for instructional purposes to assist educators, especially since participants (i.e., Struggling Writers) still, two years later, proudly talk about the responses they wrote during this study, their self esteem appearing to be well intact. By scaffolding students' writing with easy-to-follow, criteria-specific graphic organizers for writing tasks, we can help even struggling students develop their writing to such a degree, that they genuinely feel pride about their work.

\section{References}

Adams, D., Power, B., Reed, M., Reiss, P, \& Romaniak, J. (1996). Improving writing skills and related attitudes among elementary school students. Tinley Park, IL: Saint Xavier University \& IRI/Skylight. (ERIC Document Reproduction Service No. ED398595)

Alvermann, D. E. (1981, Sept./Oct.). The compensatory effect of graphic organizers on descriptive text. Journal of Educational Research, 75(1), 44-48.

Alvermann, D. E., \& Boothby, P. R. (1983). A preliminary investigation of the differences in children's retention of "inconsiderate" text. Reading Psychology: An International Quarterly, 4(3), 237-246.

Alvermann, D. E., \& Boothby, P. R. (1986). Children's transfer of graphic organizer instruction. Reading Psychology: An International Quarterly, 7, 87-100.

Anderson, T. H., \& Armbruster, Bonnie B. (1984). Studying. In P. David Pearson (Ed.) R. Barr, M. L. Kamil, \& P. Mosenthal (Sec. Eds.), Handbook of reading research. New York, NY: Longman.

Berkowitz, S. J. (1986, Spring). Effects of instruction in text organization on sixth-grade students' memory for expository reading. Reading Research Quarterly, 21(2), 161-178.

Bos, C. S., \& Vaughan, S. (2006). Strategies for teaching students with learning and behavior problems (6th ed.). Needham Heights, MA: Allyn and Bacon.

Dunston, P. J. (1992, Winter). A critique of graphic organizer research. Reading Research and Instruction, 31(2), 57-65.

Graham, S. \& Harris, K. R. (2005). Writing better: Effective strategies for teaching students with learning disabilities. Baltimore, MD: Paul H. Brookes Publishing.

Graves, D. H. (1994). A fresh look at writing. Concord, Ontario: Irwin Publishing.

Griffin, C.C., \& Tulbert,B.L.(1995). The effect of graphic organizers on students' comprehension and recall of expository text: A review of the research and implications for practice. Reading and Writing Quarterly: Overcoming Learning Difficulties, 11, 7389.

Harvey, S., \& Goudvis, A. (2000). Strategies that work: Teaching comprehension to enhance 
understanding. Markem, Ontario: Pembroke Publishers Limited.

Kim, A., Vaughn, S., Wanzek, J., \& Wei, S. (2004). Graphic organizers and their effects on reading comprehension of students with LD: A synthesis of research. Journal of Learning Disabilities. 37(2), 105-118.

Mayer, R. E. (2005). Cognitive theory of multimedia learning. In R. E. Mayer (Ed.), The Cambridge handbook of multimedia learning (pp. 31-48). New York: Cambridge University Press.

Merkley, D.M., \& Jefferies, D. (2000). Guidelines for implementing a graphic organizer. Reading Teacher, 54(4), 350.

Moore, D. W., \& Readence, J. E. (1984). A quantitative and qualitative review of graphic organizer research. Journal of Educational Research, 78, 11-17.

Newman, D. (1990). Opportunities for research on the organizational impact of school computers. Educational Researcher, 19(3), 8-13.

Price, E.A. (2008). An investigation of the use of graphic organizers coupled with a checklist to improve student response writing (Master's thesis, Mount Saint Vincent University). Retrieved from http://dc.msvu.ca:8080/xmlui/bitsteam/handle/10587/901/Elaine\%20PriceMA\%20Education.pdf? sequence $=1$.

Reinking, D. \& Pickle, M. (1993). Using a formative experiment to study how computers affect reading and writing in classrooms. In D. J. Leu \& C. K. Kinzer (Eds.), Examining central issues in literacy research, theory, and practice (pp. $263-$ 270). Chicago, IL: National Reading Conference.

Reinking, D. \& Watkins, J. (1996). A formative experiment investigating the use of multimedia book reviews to increase elementary students' independent reading: Reading research report No. 55. Athens, GA: National Reading Research Center (ERIC Document Reproduction Service No. ED398570)

Rice, G.E. (1994). Need for explanations in graphic organizer research. Reading Psychology: An International Quarterly, 15, 39-67.

Simmons, D. C., Griffin, C. C., Kameenui, E.J. (1988). Effects of teacher-constructed pre- and post-graphic organizer instruction on sixth-grade science students' comprehension and recall. Journal of Educational Research, 82(1), 15-21.

Stull, Andrew T., \& Mayer R. (2007). Learning by doing versus learning by viewing: Three experimental comparisons of learner-generated versus author-provided graphic organizers. Journal of Educational Psychology, 99(4), 808-820.

\section{Author Biographies}

Elaine A. Price is a grade seven English Language Arts teacher with the Chignecto Central Regional School Board, Truro, Nova Scotia. As a life-long learner, her C.V. includes a Master of Education and a Master of Arts in Education, with a thesis. Elaine can be contacted at pricee@ccrsb.ca.

Mary Jane Harkins teaches in the Faculty of Education at Mount Saint Vincent University in Literacy Education and Curriculum Studies. Her research interests include inclusive education, struggling readers and writers and Indigenous studies. Mary Jane can be contacted at maryjane.harkins@msvu.ca. 


\section{Appendix A}

Herringbone (Adaptation)

\section{HERRINGBONE \\ Book Response}
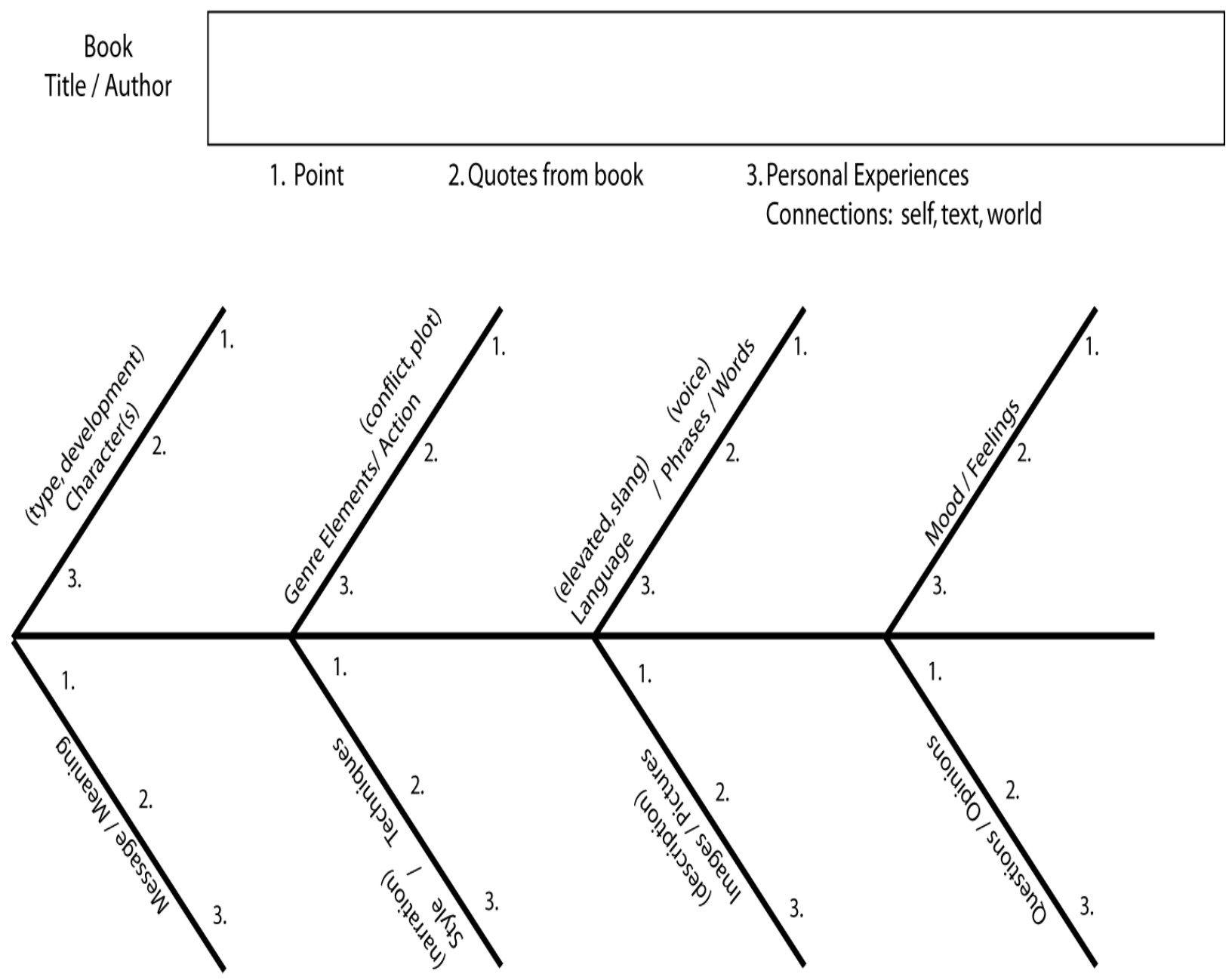


\section{Appendix B}

Expanding Ideas - (Coupled with adapted Herringbone)

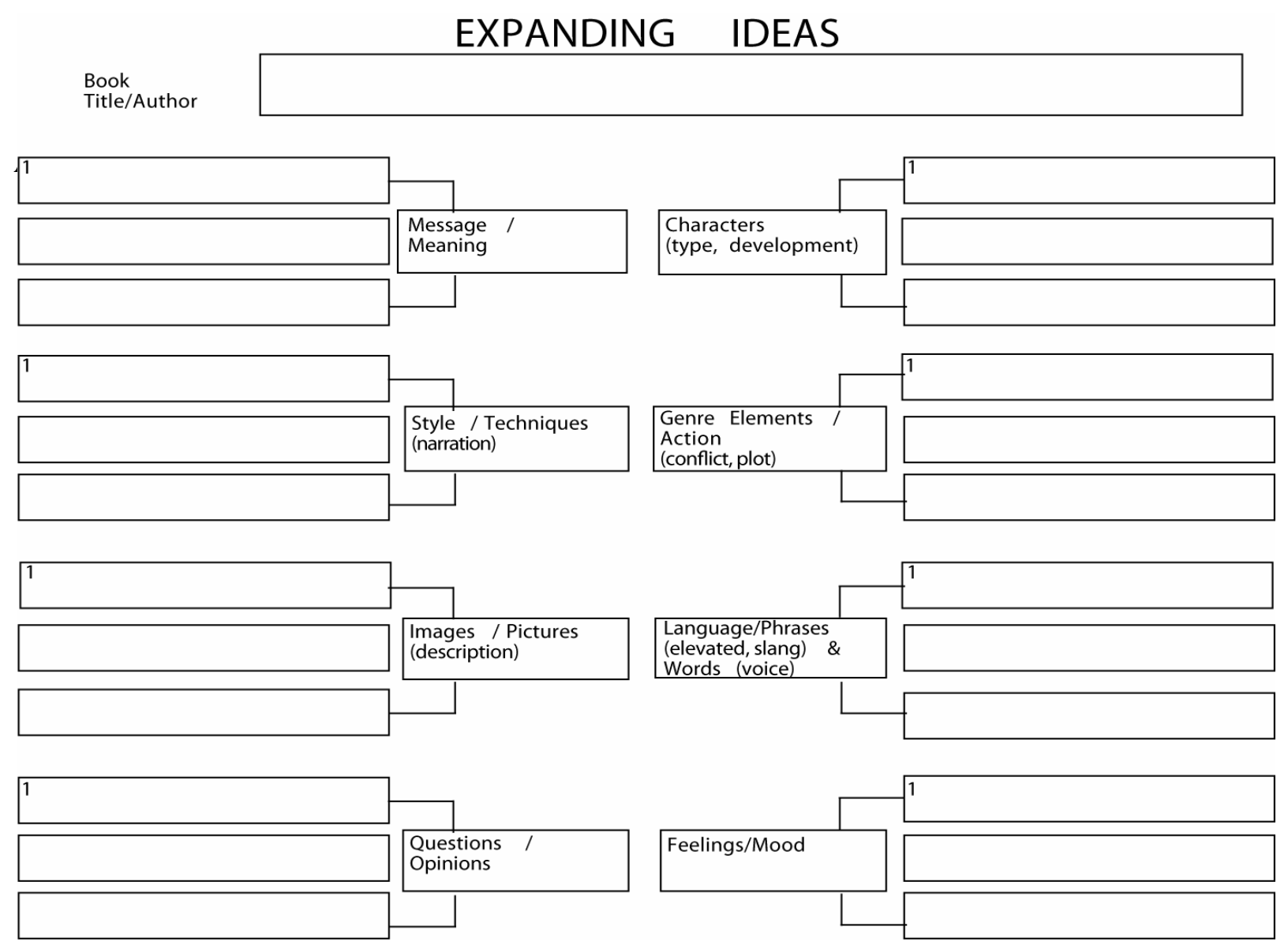


Appendix C

\section{Student information - Book Response Analysis}

Character (type, development) - any points about what the main characters look like, how they act, or their personality (tall, blonde hair, moody, insecure, friendly, etc.)

Genre Criteria / Action (conflict, plot) - What type of book is it (realistic fiction, adventure, mystery...) and what parts of the book tell you it is that kind of book. Talk about the rising action or the small problems that built up to the climax, what the major problem is - climax, and how all the small problems get resolved.

Language (elevated, slang)/ Phrases / Words (voice) - Is there a type of language used in the book that is significant or different? eg. "Waz Up?" (makes you think of a rapper or someone that dresses a certain way) This example is slang and creates a certain mood/image for you. If people are using big words or very descriptive words, each of those might create another type of mood and should be noted.

Mood/ Feelings - Are there parts in the book that make the hair on the back of your neck stand up, or that make you really feel sad or excited? These are worth noting as the mood of the book or feelings that you are made to feel through the writing.

Message/ Meaning - Sometimes a book has a message and can be a moral message that tries to tell you about good or evil. Sometimes it tries to give you an example to support a particular choice the reader could make. This would be the meaning or message in the book.

Style (narration) / Techniques - There are several techniques that authors use, for example: foreshadowing, where they give you clues to something that is important; or flashbacks, where the author has a character remember things that happened before.

Images / Pictures (description) - If there are any parts in the book that make you feel you are right there, or that cause you to relate to a place or situation you can really see in your mind's eye because they are so well described, these are important to note.

Questions / Opinions - If you come to any parts that you wonder about, feel a certain way about, or that cause you to have a particular view/thought about something, make note of them.

Expanding Ideas - In order to create an interesting paragraph about each of the areas above, you need to have at least three more points (beyond your topic sentence, quote, and possible connection) about the main idea in your paragraph.

Supporting Points - You should find proof in the text to support at least one of the points you made in your paragraph and quote those words. You can also make a connection to any of your points that would remind you of a personal experience, another text, or of a media piece, and explain yourself well enough so the reader will also see the connection.

Adhevise Notes - When you find a point about any of the areas for analysis (images, style, etc.) as you are reading, you should use your adhevise notes by writing the title of the area for analysis on the top (images, style, etc.) page number, and the exact words you want to use or quote. Then, place the note in your book to mark that spot in your book. 


\section{Appendix D}

\section{Book Response Essay Format}

Introductory paragraph:

Introduce the name of the book and the author in the first paragraph and underline the title of the book. Tell what genre the book is and explain how it is that type of genre. You could include what audience the author is targeting. You might be able to explain your support for that point by telling who the main character is in the book and what the major activity/situation is in one or two sentences without retelling the story or the ending.

Supporting paragraphs:

In the first sentence of each paragraph you should mention what the main idea is for your paragraph, but don't talk to the reader. (eg. I am going to tell you... or, The quote that shows patience is...) Next, you should talk about that main idea in your paragraph using different examples, by referring to particular parts in the book that would give evidence to support your point. Quoting the exact words to prove your point gives your idea extra strength. Remember to use quotation marks around your quote, and choose a quote that clearly shows what it is you are trying to say/prove. Your quote should naturally blend into your paragraph as if it is the next sentence or part of your next sentence. Your concluding sentence in your paragraph should sum up your paragraph. You can give your opinions about how well you think the author dealt with each of the areas to be analyzed and how they affected you personally. You can also make personal connections to your points, connections to other books, to other authors who wrote in a similar way, or make a connection to what is happening in the world. You must explain any point that you make well enough to prove what you have said.

Remember that each paragraph should begin with the main idea you are going to talk about, or a topic sentence. You should talk about this main idea and possibly give examples, but do not list them. As well, you should try to show proof by quoting, when you are trying to prove a point. Paragraphs should be at least three (compound/longer) sentences in length, although those would be short paragraphs. Five sentences or more is a good number to be able to say what you have to and give enough evidence to support your ideas, without just listing your ideas.

Concluding paragraph:

Your final/concluding paragraph should end/sum up your piece. One style is to mention every one of the main ideas you started each of your paragraphs with again, and end the concluding paragraph with a final opinion about the whole book that results from the ideas you wrote about. Check for:

- varied sentence beginnings, signal words/phrases

- run-on sentences

- short, choppy sentences that could be combined

- transition words (and, next, also, finally, then, because...)

- first/second/third person perspective is consistent

- tense is consistent (don't use I seen $=$ I saw)

- possessive agreement (My dad's house...)

- word choice (include similes, metaphors, sensory/descriptive words 


\section{Appendix E}

\section{Student Questionnaire}

Book Response

participant number:

Check beside yes or no for your correct answer.

yes

no

B1. Do you normally do a rough copy for a book response?

yes _ no __

B2. Do you think you should have to do a rough copy for a book response?

yes _ no

B3. Do you normally edit your rough copy for a book response?

yes _ no _ _

B4. Do you normally do a good copy once?

yes __ no _ _

B5. Would having to do a good copy more than once be upsetting?

yes _ no

B6. Do you like to use graphic organizers?

yes ___ no _

B7. Do you think that using a graphic organizer improves your book response writing?

yes _ no

B10. Did you do a book response before this study?

yes _ no _ n _

B11. Did you use a graphic organizer for your book response writing before this study?

yes _ no __

B12. Did you use a checklist for matters of correctness for your book response writing before this study?

B8. Which items would you prefer to use for your next book response?

Circle your choice.

a) only my notes, (not a graphic organizer, nor a checklist)

b) a book response graphic organizer only

c) a book response graphic organizer and a checklist for punctuation

B9. Which items will you use to achieve your best writing for your next book response? Circle your choice.

a) only my notes, (not a graphic organizer, nor a checklist)

b) a book response graphic organizer only

c) a book response graphic organizer and a checklist for punctuation 


\section{Appendix F}

A participant's final copy of his/her book response

written with only the Book Response Analysis Information handout.

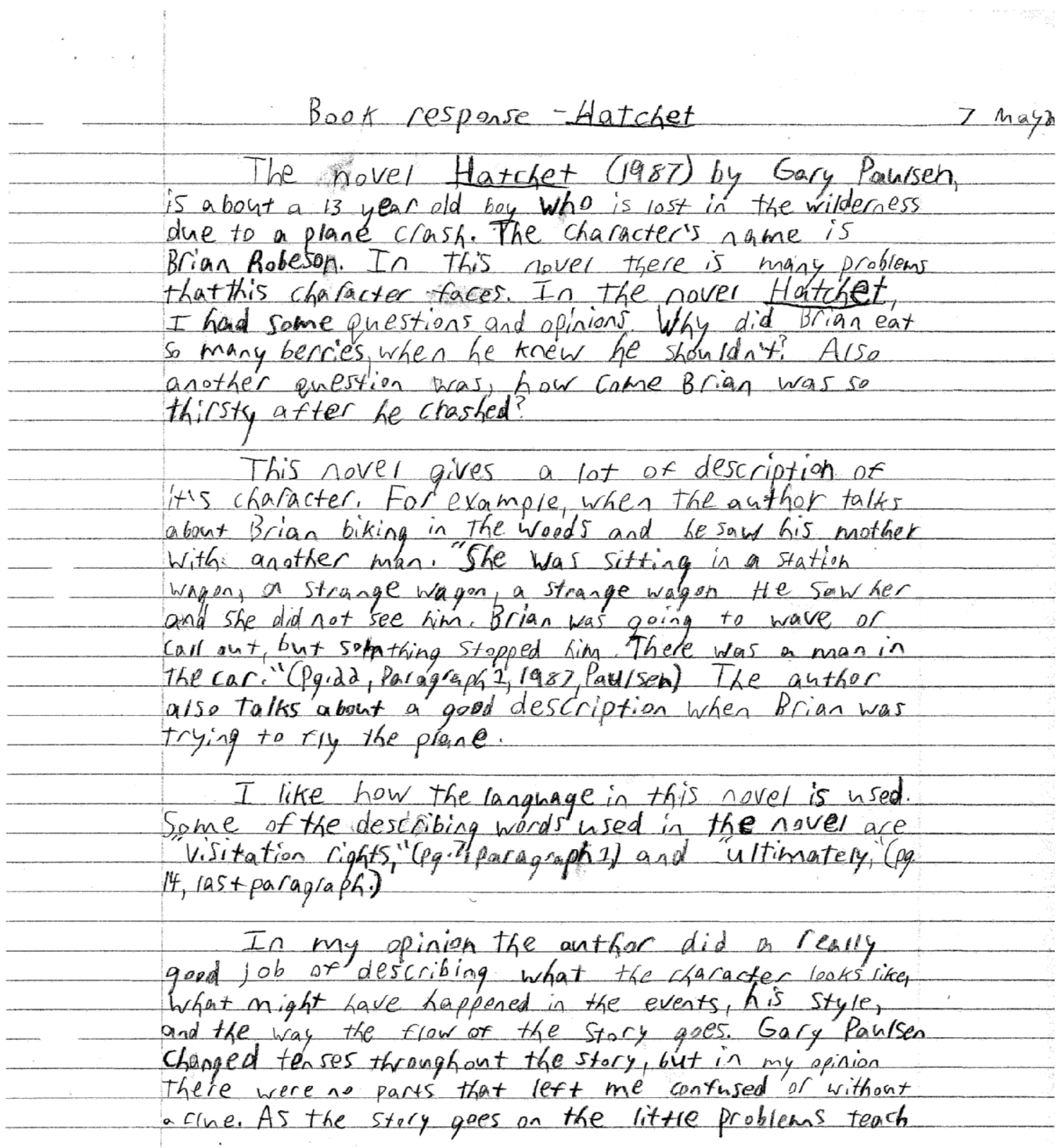


$p g \cdot h$

the character lessons, he reaches the crimax, then everything frows topether.

Their was some very exciting parts, some that rearly got me to picture what was happening, what it fent rike, how he experienced it and made connections. "He qave it a thy and it sid back toward him easily. Too easily. The prane, with the increased speed from the tilt down, swooped eagerly up and drove Brians strmach down."

The style and techniques that Gary Pausien used are a rittle complex. He uses flashbacks to terl of what hapened to brian before, possibly helping him with a problem of "inst remembering. Terling aboux the past of a character is very important, and that's what I think made the book better understanding. A good example of a flashback is when brian crashed," " a color that exploded in fis mind with the pain and he was gone, gone from it all, spiraling out into the worrd spiraling out int nothing. Notfing. The Menory was like a knite outting into him. Sicing dees into him with hate. The secret. He had been fiding his ten-speed with a friend named Terry..."

The message of this nover is man vs nature. The meaning is the t Brian would never be the same again, the experience changed his ife forever 


\section{Appendix G}

A participant's completed Herringbone Book Response Organizer (two-page organizer)

\section{HERRINGBONE}

\section{Book Response}

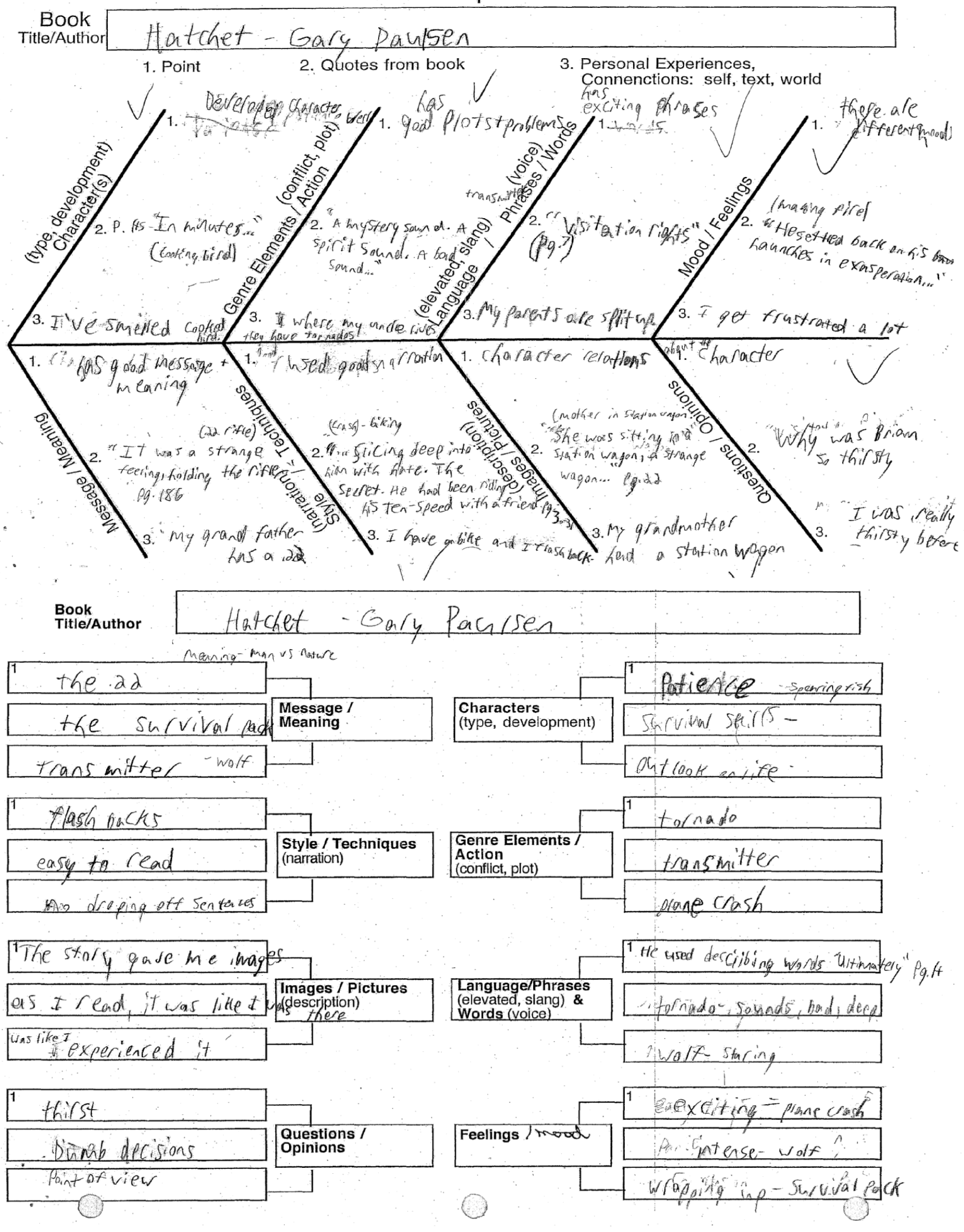




\section{Appendix $\mathrm{H}$}

A participant's final copy of his/her book response written with the Herringbone Book Response Organizer (two-page organizer).

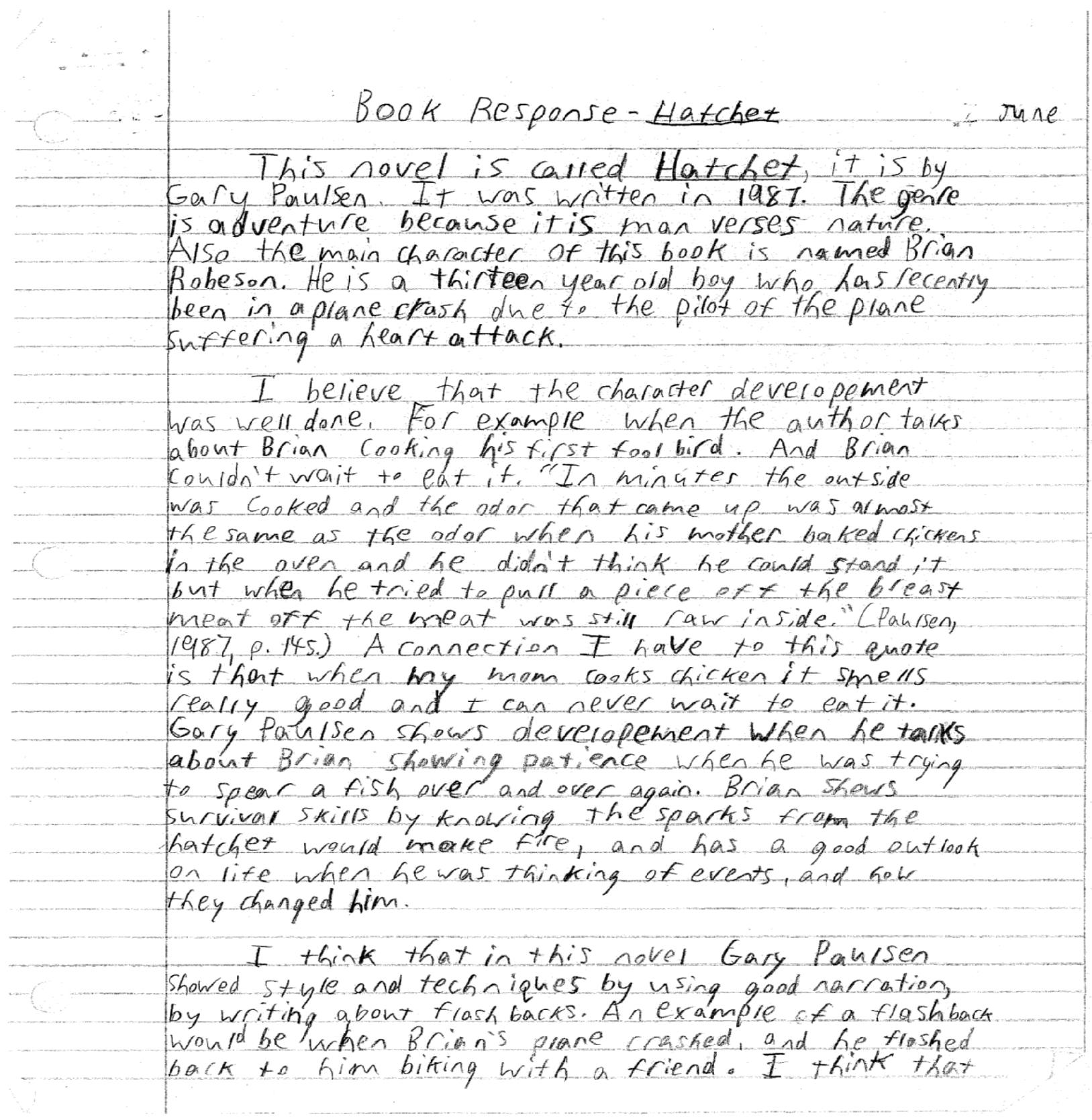


a connection to this event would be that I've

drivin in the park berore on my bike with a friend, and I think that I've flasked back before. This novel in my opinion is pretty easy to read but I think that there are no places that tolk about somthing and then drop the sentence off with missing information.

From my point of view the anthor tales about piot and probrems. An example of a problem wouldbe when the tornado fit and Brian, at first condn't figure out what the sound was. Another wourd be when Brian swam out to the plane, got the survival pack and the next day he looked through it and found the emergancy transmitter Last, one more plot would be when the pilot of the plane Brian was in fad a heartattack and brian crashed it, leaving him lost.

Through the novel I had questions and opinions. An example of a question I had about Brian was, why was he so thirsty after the prane crash? I've been very thissty hefore butnot as much as it was described. Another question is about the dumb decisiens that Brion made such as fim trying to firs fimselx. In my opinion Brian's life seems very hard to me even theng he's been through a rot, but Ithink he's going along just fine.

When Gary Paursen wrote Hatchet he used elevated language. A phrase I thanght was Cool is "Visitatien rights" (Pautsen, 1987, P.7) A connection to that wouldbe that my parents are split up. 
He also used anather describing word "Uttimater" talking about when the tornado was Eoming and Brian was trying to figure ont what the sound was.

I berieve that through this novel there are

different moods. Gary Paniseh shows these meods through talking about Bcian. An exampre would be when he was making a fire. "He setfled back on his haunches in exasperation.. "(Pacisen $19187, p$.?) A connection to that wourd be that I get frustraited somtimes. I think an exciting part from this novel would be when Brian crasked the prane. In addition I think it was intense when the wolf was staring at Brian. Finally the novel wraps up when Brian finds the survival pack.

While I read this nover it gave me images and pictures. I think that Gary Paursen did a goad job using description. An example of a part in the nover that was werr described and got me to picture what was happening was when Brian saw his mom in a station wagon with another man. While I was reading it was like I was there. I thaught the description was so gaod samtimes it was like I was there. For example when Brian was being attacked by the moose, and how it kept on attacking

\section{It seems to me that this novel has an} excellent meaning and message. I think a message would be when Brian found the 22 rifle and it said it somklow removed him. Another would be when Brian found the survival Finally in my bpinion the meaning was when Gary Paulsen wrote about the wort, standing on the cliff above Brian, staring at him.

Through this novel it taks a bout message and meaning, style and techniques, images and pictures. my opinions and questians, character deveroptueat, the conflic, plot and prablems, langhage and phirases, and feelingsand mood. Ig 'nm upl I think this nover was very well done. 